\title{
Evaluation of a new method for assessing resilience in urban aquatic social- ecological systems
}

\author{
Jonathan P. Moores $^{1}$, Sharleen Yalden ${ }^{1}$, Jennifer B. Gadd ${ }^{1}$ and Annette Semadeni-Davies ${ }^{1}$
}

\begin{abstract}
Urban aquatic social-ecological systems (SESs) comprise socio-technical elements, the built environment and its management, and natural elements (water bodies) that provide ecosystem services. Changed hydrology, poor stormwater quality, and the modification of water bodies associated with urban development brings challenges for maintaining ecosystem services provision in an urban aquatic SES. Water sensitive urban design (WSUD) has emerged as a form of development that aims to better support the provision of ecosystem services. Resilience concepts provide a basis for discriminating between WSUD and conventional development approaches. Building on an existing decision support system, a new, preliminary method for assessing resilience based on the combination of the socio-technical capacity (STC) and natural capacity (NC) of urban aquatic SESs has been developed. The STC score reflects a multicriteria assessment of the characteristics of stormwater infrastructure and management. The NC score reflects an assessment of the state and trajectory of biophysical attributes of the system associated with the provision of ecosystem services. By modeling a series of future urban development scenarios in Auckland, New Zealand, the method has been shown to discriminate between scenario outcomes within constraints associated with the biophysical and built characteristics modeled. Results are consistent with key concepts of resilience theory: outcomes are grouped in regimes and exhibit hysteresis, with the ability of WSUD to improve the state of the system strongly influenced by the presence of legacy effects. The method provides a source of additional, valuable information that complements other indicators by providing a snapshot of the interaction of catchment management effort and outcomes and indicating the likely future state of the SES. Recognizing that the method is limited to providing a relative assessment of resilience and adopts certain simplistic assumptions, further research aims to investigate assessment methods that consider other, fundamental biophysical and social properties of urban aquatic SESs.
\end{abstract}

Key Words: decision support system (DSS); natural capacity; resilience indicators; socio-technical capacity; stormwater management; urban aquatic social-ecological system; urban development scenario; water sensitive urban design (WSUD)

\section{INTRODUCTION}

Even in urban areas, natural water bodies such as streams, rivers, and estuaries can provide a range of ecosystem services. These include regulating services, such as moderating the effects of floods and providing for the assimilation of contaminants; habitat services, for instance, for aquatic invertebrates, fish, and waterfowl; and cultural services, supporting recreational activities in situ and around the margins of water bodies (Bollund and Hunhammar 1999, Alfsen et al. 2011, Lundy and Wade 2011, McDonald and Marcotullio 2011, TEEB 2011, GómezBaggethun and Barton 2013).

However, urban development brings challenges for maintaining the provision of ecosystem services; as characteristics such as land cover and building density become increasingly urban, ecosystem service provision declines (Tratalos et al. 2007, Radford and James 2013). Conventionally, urban areas are characterized by having a high proportion of impervious land covers, such as concrete, asphalt, and roofs, and highly modified drainage systems featuring piped stormwater networks discharging to engineered waterways (Woods Ballard et al. 2015). In combination, the modification of the land surface and the reticulation of drainage results in the increased generation and rapid discharge of stormwater during rainfall events, increasing the frequency of elevated stream flows (Butler and Davies 2009). In the absence of stormwater treatment to remove contaminants such as sediment and metals discharged in urban stormwater, urban water bodies are also characterized by poor water quality (Göbel et al. 2007) while the modification of water bodies and their margins results in the degradation of habitat for aquatic fauna (Riley 1998).

In recognition of these challenges, water sensitive urban design (WSUD) has emerged as an alternative to conventional forms of urban development. WSUD aims to integrate urban planning and water management to better manage, for example, water supply security, water quality in natural water bodies, flood risk, and amenity values of water bodies (Mouritz et al. 2006, Hoyer et al. 2011). Although different jurisdictions place emphasis on different aspects of WSUD (Fletcher et al. 2014), the approach is characterized by a set of core concepts. First, WSUD aims to limit runoff and contaminant generation at source by minimizing the construction of impervious surfaces, such as roads and roofs (Hoyer et al. 2011, Lewis et al. 2015, Woods Ballard et al. 2015). This can be achieved, for instance, by building clusters of multistorey dwellings to retain relatively large areas of undeveloped green space. Second, WSUD aims to maintain the functioning of natural drainage systems, rather than replacing stream networks with piped systems (Roy et al. 2008, Lewis et al. 2015, Sabbion and Perini 2017). In combination, these practices aim to maintain characteristics of catchment hydrology, including infiltration, groundwater recharge, and stream flow characteristics, similar to those that existed predevelopment. Third, WSUD uses green technologies to better manage stormwater in a way that complements its approach to land use planning (Hoyer et al. 2011, Lewis et al. 2015, Woods Ballard et al. 2015). The use of permeable paving, for instance, helps to promote infiltration and reduce

${ }^{1}$ National Institute of Water and Atmospheric Research Ltd. 
stormwater runoff. Bioretention systems, or raingardens, also provide for runoff control while providing treatment to improve stormwater quality via the removal of contaminants as stormwater infiltrates through an engineered soil media. Wetlands also provide stormwater treatment and runoff control, as well as providing habitat and amenity services. WSUD can also feature riparian planting, or the revegetation of stream banks, to improve stream habitat quality and connectivity (Lewis et al. 2015, Sabbion and Perini 2017).

The transition to WSUD has been challenged by institutional inertia (Brown 2008), arising partly from limited demonstration of its performance compared with alternatives (Roy et al. 2008). Among other objectives, WSUD aims to foster resilience in water management (Wong and Brown 2009, Woods Ballard et al. 2015), including giving water bodies the capacity to maintain ecosystem service provision at predevelopment levels in catchments undergoing urban development. In the case of urban renewal, WSUD aims to both improve the provision of ecosystem services over historical levels and afford water bodies a level of resilience that enables these improvements to be maintained. WSUD seeks to achieve these outcomes by better regulating flows and contaminant discharges, improving habitat quality and supporting cultural services. An assessment of resilience therefore provides an opportunity for discriminating between stormwaterrelated outcomes that might be achieved under WSUD and under conventional forms of urban development.

However, because resilience is often not clearly defined and may need to be inferred from indirect observations, its assessment is challenging (Carpenter et al. 2005, Resilience Alliance 2010, Quinlan et al. 2016). Accordingly, assessments of resilience have often been qualitative in nature (Resilience Alliance 2010, Birkmann et al. 2012, Nemec et al. 2013, Quinlan et al. 2016). A number of authors have described multicriteria approaches, spanning both biophysical and social indicators, for assessing resilience (Quinlan et al. 2016). For example, Milman and Short (2008) used questionnaires to elicit information from water managers to assign scores to aspects of six factors influencing resilience in urban water supply systems. In assessing watershed resilience to the effects of dam building, Nemec et al. (2013) reviewed historical literature sources to inform an expert-based rapid assessment method for assigning scores to a set of 11 leading ecological and social resilience indicators. As well as these qualitative approaches, significant research effort has been employed in the development and application of quantitative assessment methods and metrics. Allen et al. (2005) described methods to assess the relative resilience of ecological and other systems based on discontinuities in the distribution of functions operating within a system. In an application of these concepts, Nash et al. (2016) showed how differences in cross-scale functionality affected the resilience of reef ecosystems to climateinduced disturbances. In another approach, Scheffer et al. (2009) described how changes in autocorrelation and variance of response variables can act as early warning indicators of a reduction in system resilience. However, in an analysis of longterm ecological data, Burthe et al. (2016) reported both autocorrelation and variance to be poor predictors of system state, recommending that further research investigate the utility of a wider suite of statistical indicators as well as seeking to improve understanding of system behavior through empirical analyses and process-based modeling. Despite considerable progress in the development of approaches for quantifying resilience, Angeler and Allen (2016) commented on the continued need for novel indication and assessment methods that connect the multiple components of resilience. Quinlan et al. (2016) recommended that methods should be grounded in theory, aim to improve understanding of the system dynamics, and be context-specific.

Reflecting the opportunity afforded by resilience concepts to provide a basis for discriminating between WSUD and conventional approaches to urban development, and the call for investigation of innovative assessment methods, this paper describes and evaluates a new, preliminary method for assessing the resilience of urban water bodies to the stormwater-related effects of development. The platform for the method is a multicriteria decision support system (DSS) for assessing the impacts of alternative urban development scenarios on ecosystem services provided by freshwater and estuarine water bodies (Moores et al. 2014). The DSS, which has been developed for, and used in, New Zealand compares the outcomes of alternative scenarios of land use change and the management of stormwater and receiving water bodies. A suite of models predicts a range of indicators of environmental, economic, social, and cultural wellbeing, consistent with the requirements of New Zealand's Resource Management Act 1991. In this paper we describe the development, application, and evaluation of a method to extend the assessment beyond the original suite of four well-being indicators to provide for an assessment of resilience.

\section{CONCEPTUAL BACKGROUND}

\section{System definition and specified resilience}

Folke et al. (2010) defined a social-ecological system (SES) as an "integrated system of ecosystems and human society with reciprocal feedback and interdependence." We define an urban water body and its catchment as an "urban aquatic SES," conceptualized as comprising two sets of elements: (1) sociotechnical elements, which include built elements (urban land cover and stormwater management infrastructure that constitute stormwater source areas and conveyance, delivery, and control systems) and nonbuilt elements (governance frameworks, social capital, and actors that influence the form of urban development and stormwater management); and (2) natural elements, these being the water bodies, for example, streams, rivers, lakes, and estuaries, that provide ecosystem services.

Walker et al. (2004) defined the resilience of an SES as the "capacity of a system to absorb disturbance and reorganize while undergoing change so as to still retain essentially the same function, structure, identity, and feedbacks." Folke et al. (2010) distinguished between general and specified resilience, the latter term referring to the response of particular attributes of a system to a specific set of disturbances, or as Carpenter et al. (2001) put it, the "resilience of what to what?" In the context of an urban aquatic SES, we define resilience as the "combined capacity of the socio-technical and natural elements of the system to maintain ecosystem service provision while under pressure from the effects of urban development." Although this definition recognizes that the resilience of a system is not characterized by the provision of a specific level of ecosystem services, but rather by the response 
Fig. 1. Assessment of system resilience according to the combination of socio-technical and natural capacity.

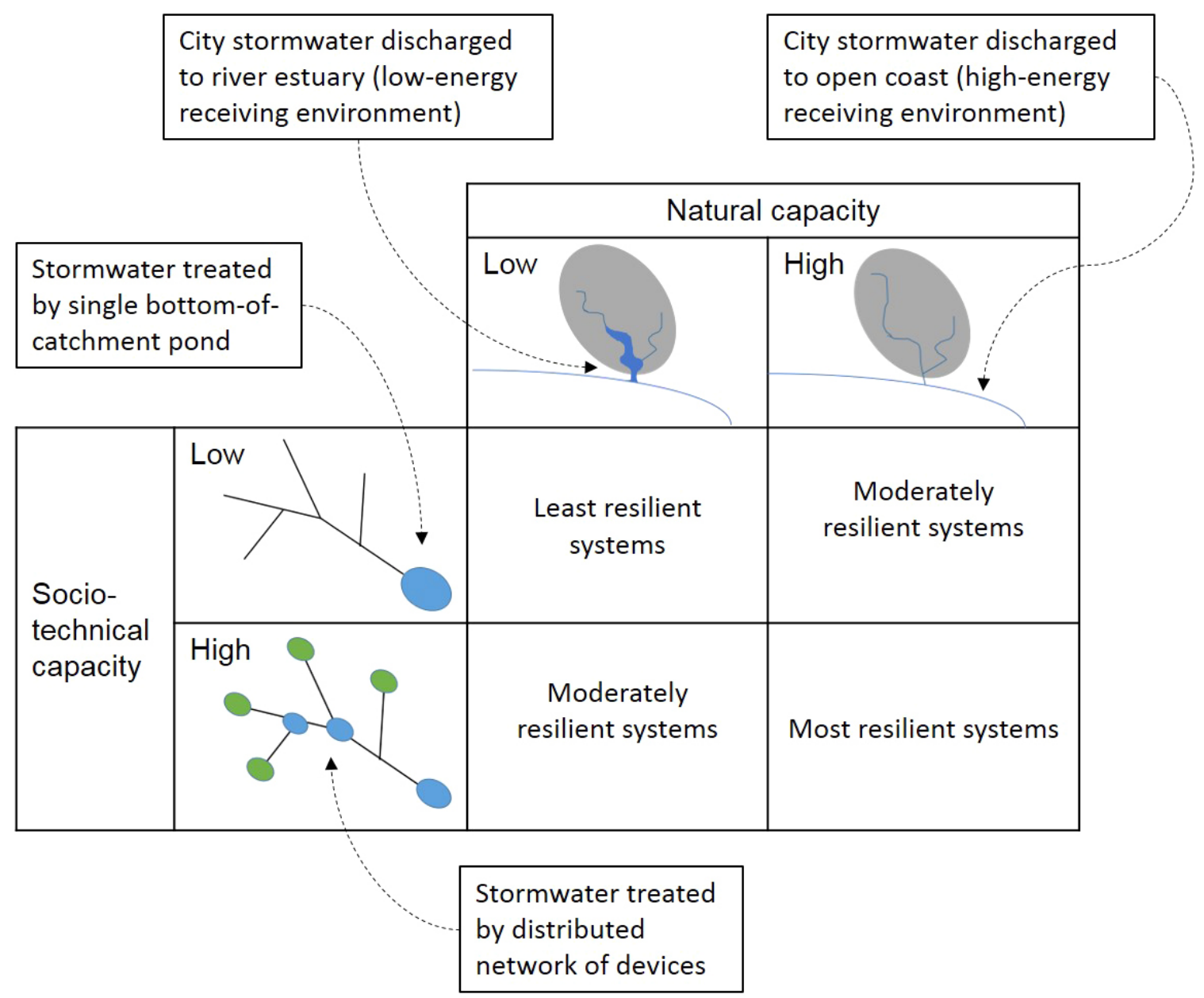

of the system to changes in forcing variables, the methods described in this paper place an emphasis on assessing the resilience of a system to provide ecosystem services at their predevelopment levels. The definition incorporates the potential for socio-technical elements of the system to both moderate the effects of urban development and substitute for the provision of ecosystem services by natural elements. A stormwater treatment pond might, for instance, provide some in situ habitat services that partly substitute for the loss of a natural water body.

\section{Assessment framework}

Although social and ecological components of an SES are interconnected, an assessment of their respective contribution to system resilience can be informative as part of developing an understanding of the state of the system as a whole (Nemec et al. 2013). From the definition given above, the resilience of an urban aquatic SES may be assessed by evaluating (1) the capacity of socio-technical elements of the system to moderate the effects of urban development; and (2) the capacity of natural elements to absorb any residual effects. Resilience is highest when effects such as the degradation of water quality are moderated by the effective treatment of stormwater and there exists a high natural capacity to absorb residual quantities of contaminants discharged to receiving water bodies (Fig. 1). High socio-technical capacity can be represented by a city that employs stormwater interventions at multiple locations throughout a catchment. Such an approach aims to minimize the generation of stormwater contaminants, for instance by implementing source controls at the private lot scale, as well as capturing residual contaminants in treatment devices (such as bioretention or wetlands) distributed across the stormwater network. Low socio-technical capacity might exist in a city where stormwater management follows a drainage-focused stormwater management approach, the emphasis of which is to quickly route stormwater through the network with, at best, stormwater treatment delivered through a single device at the catchment outlet. An example of a system with high natural capacity is one in which stormwater is discharged from a relatively small catchment to an extensive high-energy receiving environment. At the other end of the spectrum, natural capacity is likely to be much lower where a receiving environment is small, depositional, and receives stormwater from a relatively large and fully urbanized catchment.

\section{Assessment of socio-technical capacity}

The assessment of socio-technical capacity involves considering the way in which the built environment and related planning and 
management activities support the provision of ecosystem services by natural elements. This involves a multicriteria assessment of the extent to which various attributes found to promote resilience feature in any given urban development scenario. Moores and Semadeni-Davies (2015) evaluated resilience criteria for their relevance to the management of urban water bodies. While a range of strategies and principles that promote resilience in urban systems have been described by previous authors, most have in common the need for systems to incorporate redundancy, diversity, and adaptability in both technical and social elements (Walker and Salt 2006, Ahern 2011, Allan and Bryant 2011, Albers and Deppisch 2013). Within the context of the DSS, in which an urban aquatic social-ecological system is represented purely by its physical characteristics, Moores and Semadeni-Davies (2015) found that a number of technical criteria, especially those described by Ahern (2011), provided the greatest utility for distinguishing between alternative urban development and stormwater management scenarios. The following five such criteria were therefore adopted for the assessment of socio-technical capacity:

- Multifunctionality: the extent to which stormwater management supports the provision of multiple ecosystem services, for instance, through regulating flows and water quality in support of habitat, provisioning, and cultural services downstream and in providing habitat services in situ;

- Modularity: the extent to which stormwater management is delivered by multiple, replicated groups of devices, for example, combinations of bioretention, wetlands, or ponds, across a range of scales;

- Redundancy: the extent to which stormwater management incorporates spare capacity to maintain its performance under changed conditions, such as increased levels of impervious land cover resulting from urban infill development and altered rainfall regimes associated with climate change;

- Diversity: the extent to which stormwater management is delivered by multiple, different devices, for example, bioretention, wetlands, or ponds, to perform across a range of environmental conditions; and

- Connectivity: the extent of natural drainage networks linking headwater streams to receiving water bodies, such as estuaries or lakes, including connectivity along the margins of water bodies.

\section{Assessment of natural capacity}

The assessment of natural capacity involves considering the vulnerability of a water body to undergoing a change from its current state, or regime, to some less desirable state (Walker et al. 2004), where regimes are distinguished both by biophysical characteristics, such as water quality and the make-up of biological communities, and the associated level of ecosystem services provided. This assessment therefore involves making predictions of the future level of ecosystem service provision, given knowledge of the current state of the system. It requires an assessment of the likelihood in the foreseeable future that one or more key biophysical attributes of the system associated with the provision of ecosystem services will undergo a change in regime, or enter a zone of increased vulnerability to effects, such as water and sediment quality degradation, arising from the discharge of stormwater. Such an assessment is based on information on the current state and trajectory of key system response variables. Figure 2 illustrates contrasting system responses to an increase in the level of urban development. Following development, system $\mathrm{A}$ is assessed as having low natural capacity because the state of the biophysical attribute is rapidly approaching a zone of vulnerability and, potentially, could undergo a change from Regime 1 to Regime 2 in the foreseeable future, with a resulting loss in ecosystem service provision. In contrast, system B is assessed as having high natural capacity because the state of the biophysical attribute has hardly changed over time, despite the same increase in the level of urban development. This illustration is deliberately simplistic and, although the current system state and trajectory are important sources of information, any prediction of future state is also contingent upon an understanding of the way in which a system responds to forcing variables. In the example presented in Figure 2, a linear response is assumed. In contrast, SESs are widely understood to follow nonlinear responses, exhibit hysteresis, and be subject to crossscale interactions (Scheffer et al. 2001, Kinzig et al. 2006). Recognition of uncertainty in system dynamics is therefore an important cautionary consideration when making predictions of the future level of ecosystem service provision from information on the historical and current state of a system alone.

Fig. 2. Illustration of the way in which differences in the trajectory of biophysical attributes during the period of urban development influence the assessment of natural capacity, with system A assessed as having lower natural capacity than system B postdevelopment. Regime 2 represents a system state with reduced ecosystem service provision.

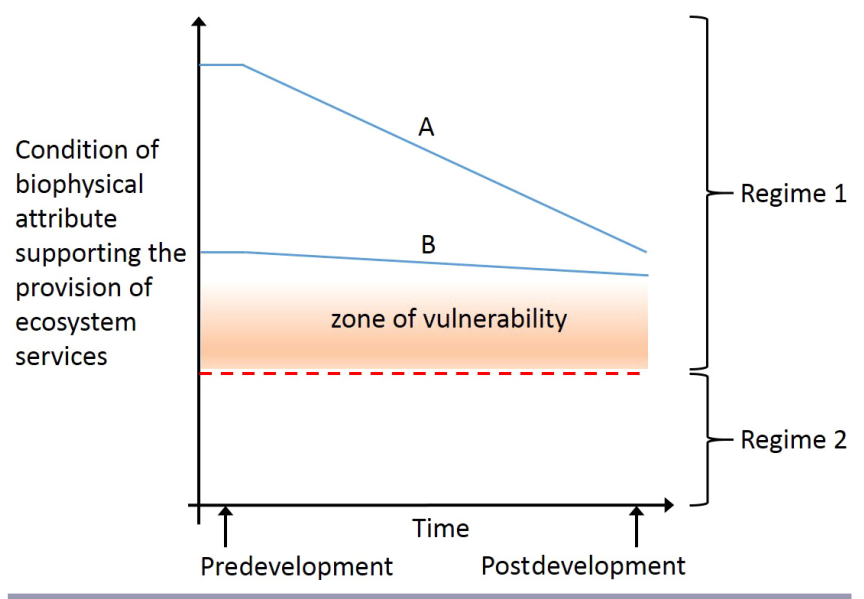

\section{METHODS}

\section{Overview of the DSS}

The DSS is a linked suite of models executed from an MS Excel platform (Moores et al. 2014). Implementation of the DSS for a given study area involves, first, spatial definition of catchment and water body (streams and estuaries) model units and second, entering parameter values that reflect the baseline environmental condition of each of these units, derived from analysis of land 
Fig. 3. Relationships between decision support system (DSS) inputs, predictions of relevant biophysical indicators, and the calculation of resilience indicator scores.

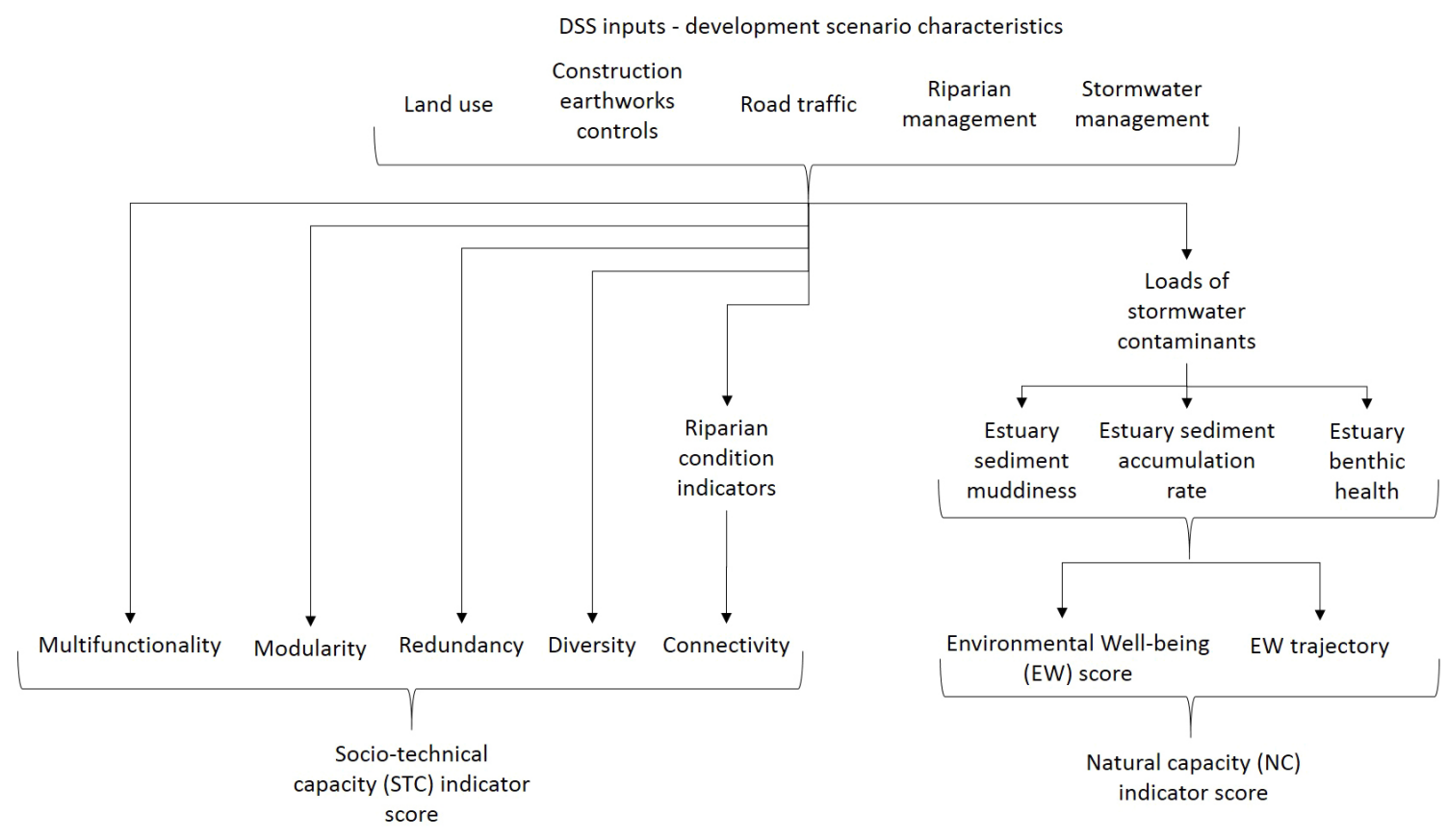

use information and the results of environmental monitoring programs. Urban development scenarios are then modeled by entering inputs representing the postdevelopment catchment condition, 50 years into the future. These inputs represent projections of land use, construction earthworks controls, road traffic, stormwater management, and riparian (stream bank) management characteristics (Fig. 3, Table 1). The specification of scenario inputs can be based on development forecasts, for instance guided by population projections, or can be completely speculative. The models embedded within the DSS make predictions of a range of indicators, including several relating to the physical and ecological condition of both riverine and estuarine water bodies. Of most relevance for the prediction of the resilience indicators are: a contaminant load model, providing estimates of annual catchment loads of sediment, copper, lead, and zinc; an estuary sediment quality model, providing estimates of estuarine sediment accumulation rates, sediment texture and sediment metal concentrations; and an urban stream Bayesian Network model, providing estimates of a range of stream and riparian ecological indicators (Moores et al. 2014). Predictions are made at an annual time step over a 50-year time horizon.

\section{Calculation of resilience indicator scores}

\section{Socio-technical capacity indicator}

The socio-technical capacity (STC) indicator score is the mean of scores calculated for the five criteria: multifunctionality; modularity; redundancy; diversity; and connectivity (Fig. 3, Table 1). With the exception of the connectivity score, the calculations involve the following steps. First, a "raw" score is assigned to each criterion based on the presence or level of certain characteristics that reflect DSS inputs and outputs associated with a given development scenario (Table 2). Second, each raw score is scaled to reflect the potential spatial extent of the respective STC criterion, reflecting the proportions of the catchment occupied by conventional and WSUD forms of development. Finally, each scaled score is normalised over the range $0-1$.

Raw scores for the multifunctionality, modularity, redundancy, and diversity criteria are assigned as follows. The raw multifunctionality score is the number of the following ecosystem services likely to be supported in a given scenario: water clarity; toxicity regulation; flow regulation; habitat, provisioning, and cultural services relating to receiving water bodies; and in situ habitat, provisioning, and cultural services relating to stormwater management devices. Assessments of water sensitive forms of urban development in Europe and North America have reported a high level of multifunctionality, relative to conventional approaches (Ahern 2011, Hoyer et al. 2011). Consistent with these assessments, higher scores are associated with more effective stormwater treatment and the use of green technologies associated with the presence of WSUD development.

The raw modularity score is the number of scales at which there are likely to be opportunities to build modularity into stormwater management. Three scales of modularity are possible: site, neighborhood, and subcatchment, all of which are assessed as being feasible under WSUD greenfield development scenarios. Modular features of WSUD include site-scale source control measures such as permeable paving and rainwater harvesting, neighborhood-scale bioretention, and treatment wetlands located at subcatchment scale (Hoyer et al. 2011, Lewis et al. 2015, Woods Ballard et al. 2015). Although modularity has featured in urban renewal projects such as green alley programs in the U.S. (Ahern 
Table 1. Summary description of decision support system (DSS) inputs and modeled variables involved in the calculation of resilience indicator scores.

\begin{tabular}{|c|c|c|}
\hline Attribute & Description & Role \\
\hline \multicolumn{3}{|l|}{ DSS Inputs } \\
\hline Land use & $\begin{array}{l}\text { Proportion ( } \%) \text { of catchment in each of } 15 \text { land } \\
\text { use classes (pre- and postdevelopment), } \\
\text { including water sensitive urban design (WSUD) } \\
\text { classes featuring relatively low levels of } \\
\text { imperviousness. }\end{array}$ & $\begin{array}{l}\text { Calculation of loads of sediment and metals } \\
\text { by DSS contaminant load model. Prediction } \\
\text { of riparian indicators by DSS urban stream } \\
\text { Bayesian Network model. Prediction of } \\
\text { multifunctionality, modularity, redundancy, } \\
\text { and diversity indicator scores (for calculation } \\
\text { of socio-technical capacity [STC] score). }\end{array}$ \\
\hline $\begin{array}{l}\text { Construction } \\
\text { earthworks controls }\end{array}$ & $\begin{array}{l}\text { Effectiveness of erosion and sediment controls } \\
\text { during land development, expressed as load } \\
\text { reduction }(\%) \text {. }\end{array}$ & $\begin{array}{l}\text { Calculation of loads of sediment by DSS } \\
\text { contaminant load model. }\end{array}$ \\
\hline Road traffic & $\begin{array}{l}\text { Change in vehicle numbers from } \\
\text { predevelopment }(\%) \text {. }\end{array}$ & $\begin{array}{l}\text { Calculation of loads of sediment and metals } \\
\text { by DSS contaminant load model. }\end{array}$ \\
\hline $\begin{array}{l}\text { Stormwater } \\
\text { management }\end{array}$ & $\begin{array}{l}\text { Effectiveness of stormwater treatment in areas } \\
\text { of urban land uses (pre- and postdevelopment), } \\
\text { expressed as load reduction (\%). }\end{array}$ & $\begin{array}{l}\text { Calculation of loads of sediment and metals } \\
\text { by DSS contaminant load model. } \\
\text { Prediction of multifunctionality, modularity, } \\
\text { redundancy, and diversity indicator scores (for } \\
\text { calculation of STC score). }\end{array}$ \\
\hline Riparian management & $\begin{array}{l}\text { Proportion }(\%) \text { of stream length with vegetated } \\
\text { margins (natural and managed, pre- and } \\
\text { postdevelopment). }\end{array}$ & $\begin{array}{l}\text { Prediction of riparian indicators by DSS } \\
\text { urban stream Bayesian Network model. }\end{array}$ \\
\hline \multicolumn{3}{|l|}{ Modeled variables } \\
\hline $\begin{array}{l}\text { Loads of stormwater } \\
\text { contaminants }\end{array}$ & $\begin{array}{l}\text { Loads of sediment (T/yr), copper, lead, and zinc } \\
(\mathrm{kg} / \mathrm{yr}) \text { discharged from the catchment. }\end{array}$ & $\begin{array}{l}\text { Prediction of estuary sediment muddiness, } \\
\text { sediment accumulation rate, and sediment } \\
\text { metal concentrations by DSS estuary sediment } \\
\text { quality model. }\end{array}$ \\
\hline $\begin{array}{l}\text { Estuary sediment } \\
\text { muddiness }\end{array}$ & $\begin{array}{l}\text { Indicator (range } 0-1) \text { derived from proportion } \\
(\%) \text { of estuary bed surface sediments in silt and } \\
\text { clay grain size fractions. }\end{array}$ & Prediction of EW indicator score. \\
\hline $\begin{array}{l}\text { Estuary sediment } \\
\text { accumulation rate }\end{array}$ & $\begin{array}{l}\text { Indicator (range } 0-1) \text { derived from accumulation } \\
\text { rate of estuary bed sediments }(\mathrm{mm} / \mathrm{yr}) \text {. }\end{array}$ & Prediction of EW indicator score. \\
\hline Estuary benthic health & $\begin{array}{l}\text { Indicator (range } 0-1) \text { derived from sediment } \\
\text { metal concentrations }(\mathrm{mg} / \mathrm{kg} \text { ). }\end{array}$ & Prediction of EW indicator score. \\
\hline $\begin{array}{l}\text { Environmental Well- } \\
\text { being }(\mathrm{EW}) \text { score }\end{array}$ & $\begin{array}{l}\text { Indicator (range } 0-1 \text { ) derived from estuary } \\
\text { sediment muddiness, sediment accumulation rate } \\
\text { and benthic health indicators. }\end{array}$ & $\begin{array}{l}\text { Prediction of natural capacity (NC) indicator } \\
\text { score. }\end{array}$ \\
\hline $\begin{array}{l}\text { Stream-riparian } \\
\text { connectivity }\end{array}$ & $\begin{array}{l}\text { Indicator (range } 0-1 \text { ) of extent of stream bank } \\
\text { modification derived from proportion }(\%) \text { of } \\
\text { catchment in urban land use classes. }\end{array}$ & $\begin{array}{l}\text { Calculation of connectivity indicator score } \\
\text { (for calculation of STC score). }\end{array}$ \\
\hline In-stream barriers & $\begin{array}{l}\text { Indicator (range } 0-1) \text { of prevalence of structures } \\
\text { such as culverts and weirs derived from } \\
\text { proportion }(\%) \text { of catchment in urban land use } \\
\text { classes. }\end{array}$ & $\begin{array}{l}\text { Calculation of connectivity indicator score } \\
\text { (for calculation of STC score). }\end{array}$ \\
\hline
\end{tabular}

2011), only two scales (site and neighborhood) are assessed as being feasible under WSUD brownfield redevelopment scenarios, reflecting the more constrained, piecemeal footprint of brownfield development projects (Lewis et al. 2015). Conventional development scenarios are assessed as providing no opportunities for modularity, reflecting the prevalence of "drainage-focused" approaches to stormwater management described above.
The raw redundancy score reflects the level of spare capacity in a given scenario and the number of ways in which spare capacity might be provided. The specification of the level of spare capacity is independent of the form of development, being selected by the user of the DSS in the range "none" to "high." This reflects the engineering principle that the design of reticulated drainage networks should routinely incorporate some level of redundancy (Butler and Davies 2009). Three options for providing spare 
Table 2. Development scenario characteristics that influence the calculation of scores for each of the five socio-technical capacity criteria (influencing characteristics indicated with " $\mathrm{x}$ ").

\begin{tabular}{|c|c|c|c|c|c|}
\hline \multirow[b]{2}{*}{ Development scenario characteristics } & \multicolumn{5}{|c|}{ Socio-technical criteria } \\
\hline & $\begin{array}{l}\text { Multifunctio- } \\
\text { nality }\end{array}$ & Modularity & Redundancy & Diversity & Connectivity \\
\hline Presence of stormwater treatment & $\mathrm{x}$ & & & & \\
\hline Effectiveness of stormwater treatment & $\mathrm{x}$ & & & $\mathrm{x}$ & \\
\hline Effectiveness of stormwater quantity control & $\mathrm{x}$ & & & & \\
\hline $\begin{array}{l}\text { Level of spare capacity in stormwater management } \\
\text { system }\end{array}$ & & & $\mathrm{x}$ & & \\
\hline $\begin{array}{l}\text { Presence of water sensitive urban design } \\
\text { development }\end{array}$ & $\mathrm{x}$ & $\mathrm{x}$ & $\mathrm{x}$ & $\mathrm{x}$ & \\
\hline $\begin{array}{l}\text { Form of land development: greenfield or } \\
\text { brownfield }\end{array}$ & & $\mathrm{x}$ & $\mathrm{x}$ & & \\
\hline Extent of riparian vegetation (total and managed) & & & & & $\mathrm{x}$ \\
\hline Extent of channel-riparian connectivity & & & & & $\mathrm{x}$ \\
\hline Extent of instream barriers & & & & & $\mathrm{x}$ \\
\hline
\end{tabular}

capacity are contemplated: greenfield land set-aside; the sizing of "end-of-pipe" stormwater management devices such as ponds and wetlands; and the sizing of "at-source" stormwater management devices such as rain tanks and bioretention devices. Only WSUD greenfield development scenarios provide for spare capacity to be provided in all three ways, for the following reasons. Land set-aside, which enables strategies involving the incremental addition of capacity (Semadeni-Davies 2012) does not apply to brownfield development scenarios, reflecting a likely lack of available space (Lewis et al. 2015), while at-source sizing does not apply to conventional (non-WSUD) greenfield development scenarios because source control is a stormwater management practice associated specifically with WSUD (Lewis et al. 2015, Woods Ballard et al. 2015).

The raw diversity score is the number of types of stormwater treatment devices likely to be employed, with a maximum of three: wetlands, ponds, and at-source devices. The number of device types is higher in scenarios specifying relatively high levels of stormwater treatment and using green technologies associated with the presence of WSUD land use. This reflects the WSUD practice of employing stormwater "treatment trains," where a range of treatment devices are employed in series to maximize the potential for contaminant capture (Hoyer et al. 2011, Lewis et al. 2015, Woods Ballard et al. 2015).

In contrast to the other criteria, the connectivity score is the average of scores estimated for four precursor variables that each already fall in the range $0-1$; hence, there is no scaling or normalizing step involved in its calculation. The riparian vegetation extent score reflects the proportion of the stream network that has vegetated margins, supporting its functioning as an ecological corridor. The managed extent of riparian vegetation score reflects the proportion of the stream network subject to active restoration and maintenance. It is adopted as a proxy for the delivery of cultural ecosystem services by a stream network, with active management assumed to support greater public access, for instance through community involvement in restoration programs. The stream-riparian connectivity score reflects the degree to which stream banks are modified and is adopted as an indicator of connectivity between aquatic and terrestrial environments. Lower scores reflect hard engineering practices such as bank reinforcing and channelization, assessed as being more prevalent under conventional development scenarios than under WSUD, with its emphasis on preserving the natural characteristics of drainage networks (Roy et al. 2008, Lewis et al. 2015, Sabbion and Perini 2017). The same assessment is made in relation to the final variable, the in-stream barriers score. This score reflects the prevalence of structures such as culverts and weirs that limit connectivity by acting as barriers to the movement of fish within the stream network.

\section{Natural capacity indicator}

The natural capacity (NC) indicator score is derived from the postdevelopment score and trajectory of the environmental wellbeing (EW) indicator modeled by the DSS (Fig. 3 and Table 1). EW is an integrating indicator that provides an overview of the biophysical condition of a receiving water body, reported on a five-category scale (low, low-medium, medium, medium-high, and high). The EW score (range $0-1$ ) is calculated as the mean of normalized scores (also range $0-1$ ) for a set of subindicators. Reflecting the coastal setting of the research described here, EW was calculated from scores for three leading estuarine biophysical subindicators predicted by models embedded in the DSS: benthic health, an indicator of the condition of estuary bed macroinvertebrate communities; muddiness, the proportion of estuary bed sediments that are clay and silt sized; and sediment accumulation rate, the average annual rate of sediment deposition on the estuary bed. Because estuarine bed sediment quality and ecology are important for the provision of a range of habitat, provisioning, and cultural services (Thrush et al. 2013), the state and trajectory of the EW score is assumed to be a reasonable source of information for assessing the capacity of the system to support ecosystem service provision. Although calculation of EW in other settings, such as lake catchments, would be based on a different set of subindicators, the same principle would apply: the EW score should reflect biophysical conditions that are influential for the provision of ecosystem services. 
Table 3. Natural capacity (NC) score based on combination of environmental well-being (EW) level and direction and rate of change in EW ("Med" = medium).

\begin{tabular}{cccccc}
\hline \hline & \multicolumn{4}{c}{ Level of EW at the end of the development scenario } \\
\cline { 2 - 5 } Rate of change in $\mathrm{EW}^{\dagger}$ & Low & Low/Med & Med & Med/High & High \\
\hline Improvement & 0.25 & 0.5 & 0.75 & 1 & 1 \\
No change & 0 & 0.25 & 0.5 & 0.75 & 0.5 \\
Slow decline & 0 & 0 & 0.25 & 0.25 & 0.75 \\
Medium decline & 0 & 0 & 0 & 0.5 & 0.25 \\
Fast decline & 0 & 0 & 0 & 0.25 \\
\hline
\end{tabular}

${ }^{\dagger}$ Over the final 10 years of the development scenario.

The NC score is assessed according to the combination of the EW score at the end of the assessment period and the direction and rate of change in the EW score over the final 10 years of the assessment (Table 3). The rate of change in EW, calculated as [EW (year 50) - EW(year 40)]/10, is assigned to one of five categories. The categories "improvement," "no change," and "fast decline" apply where the rate of change would lead to an improvement, no change, or a one-level decline in EW, respectively, within the 10 years following the end of the 50 -year model time horizon. The categories "medium decline" and "slow decline" apply where the rate of change would lead to a one-level decline in EW within a 20- and 30-year period, respectively.

$\mathrm{NC}$ scores lie in the range 0 to 1 , being highest where EW is either modeled as being "high" or projected to become "high" within 10 years. NC scores are lowest where EW is modeled as either being "low" or projected to become "low" within 10-30 years. Intermediate NC scores follow a gradient reflecting the EW score and trajectory at the time of the assessment (Table 3).

\section{Reporting of indicator scores}

The STC and NC scores assessed by the DSS are plotted on a two-dimensional surface, with the STC score on the X-axis and the NC score on the y-axis (Fig. 4). Based on the hypothesis that resilience to the effects of urban development is greatest in systems exhibiting high levels of both natural and socio-technical capacity, a more resilient outcome plots toward the upper righthand corner, while a more vulnerable one plots toward the lower left-hand corner.

\section{Lucas Creek catchment study}

Description of study area

We demonstrated and evaluated the performance of the resilience indicators by modeling a range of future urban development scenarios in the Lucas Creek catchment on the northern fringe of New Zealand's largest city, Auckland. The catchment covers an area of $37 \mathrm{~km}^{2}$, contains streams with a total length of $44 \mathrm{~km}$ and drains to the 150 ha Lucas Creek tidal inlet, an estuary of the Upper Waitemata Harbour. The catchment has undergone significant urban development since the 1960s (Fig. 5) and is relatively data rich as a result of various environmental monitoring and modeling studies. In a previous application of the DSS, assessments of changes in stream and estuarine indicators over the period 1960 to 2010 were found to correspond well with monitoring data, providing confidence in the capability of the system (Moores et al. 2014). In the present study, the STC score was derived from weighted-averages of the relevant urban development, stormwater management, and stream management characteristics in each of four subcatchments of the Lucas Creek catchment. Input data on historical development was derived from analysis of aerial photographs, population census data, and local government stormwater planning documents (Moores et al. 2014). The NC score was derived from the state and trajectory of the EW score predicted for the Lucas Creek tidal inlet receiving environment.

Fig. 4. Surface for assessment of system resilience based on its hypothesized relationship with the combination of sociotechnical and natural capacity scores (the lighter the shading, the more resilient the system state).

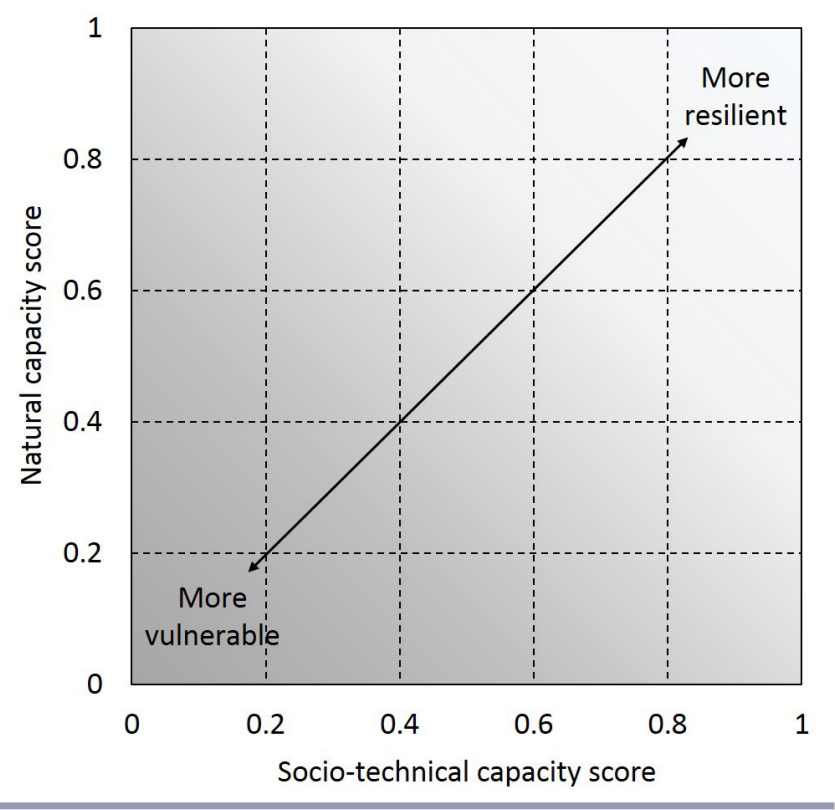

Urban development scenarios

The assessment considered seven urban development scenarios for the period 2010-2060, each of which accommodated identical dwelling numbers, areas of industrial and commercial land use, and increases in road traffic. The scenarios differed in terms of assumptions regarding prior development, dwelling density, the timing of development, mitigation of stormwater contaminants, 
Table 4. Characteristics of urban development scenarios, Lucas Creek catchment.

\begin{tabular}{|c|c|c|c|c|c|c|}
\hline Scenario & $\begin{array}{l}\text { Catchment baseline } \\
\text { condition }\end{array}$ & $\begin{array}{l}\text { Form of } \\
\text { development }\end{array}$ & $\begin{array}{l}\text { Stormwater } \\
\text { management }\end{array}$ & $\begin{array}{l}\text { Riparian } \\
\text { management }\end{array}$ & $\begin{array}{c}\text { Year } \\
\text { development } \\
\text { begins } \\
\end{array}$ & $\begin{array}{c}\text { Year } \\
\text { development } \\
\text { ends } \\
\end{array}$ \\
\hline 1 & $\begin{array}{l}\text { Posthistoric urban } \\
\text { development }\end{array}$ & $\begin{array}{l}\text { Greenfield low } \\
\text { density }\end{array}$ & Conventional & Conventional & 2010 & 2035 \\
\hline 2 & $\begin{array}{l}\text { Posthistoric urban } \\
\text { development }\end{array}$ & $\begin{array}{l}\text { Greenfield and } \\
\text { infill high density } \\
\text { WSUD }^{\dagger}\end{array}$ & Best possible & Best possible & 2010 & 2035 \\
\hline 3 & $\begin{array}{l}\text { Rural, as per } \\
\text { prehistoric urban } \\
\text { development }\end{array}$ & $\begin{array}{l}\text { Greenfield medium- } \\
\text { high density }\end{array}$ & Conventional & Conventional & 2010 & 2035 \\
\hline 4 & $\begin{array}{l}\text { Rural, as per } \\
\text { prehistoric urban } \\
\text { development }\end{array}$ & $\begin{array}{l}\text { Greenfield high } \\
\text { density WSUD }\end{array}$ & Best possible & Best possible & 2010 & 2035 \\
\hline 5 & $\begin{array}{l}\text { Fictional relatively } \\
\text { pristine catchment }\end{array}$ & $\begin{array}{l}\text { Greenfield medium- } \\
\text { high density }\end{array}$ & Conventional & Conventional & 2010 & 2035 \\
\hline 6 & $\begin{array}{l}\text { Fictional relatively } \\
\text { pristine catchment }\end{array}$ & $\begin{array}{l}\text { Greenfield high } \\
\text { density WSUD }\end{array}$ & Best possible & Best possible & 2010 & 2035 \\
\hline 7 & $\begin{array}{l}\text { Fictional relatively } \\
\text { pristine catchment }\end{array}$ & $\begin{array}{l}\text { Greenfield medium- } \\
\text { high density }\end{array}$ & Conventional & Conventional & 2036 & 2060 \\
\hline
\end{tabular}

${ }^{\dagger}$ Water sensitive urban design

Fig. 5. Lucas Creek catchment boundary, subcatchment boundaries, and estuary, showing extent of urban land cover (shaded dark grey) in (a) 1960 and (b) 2010.

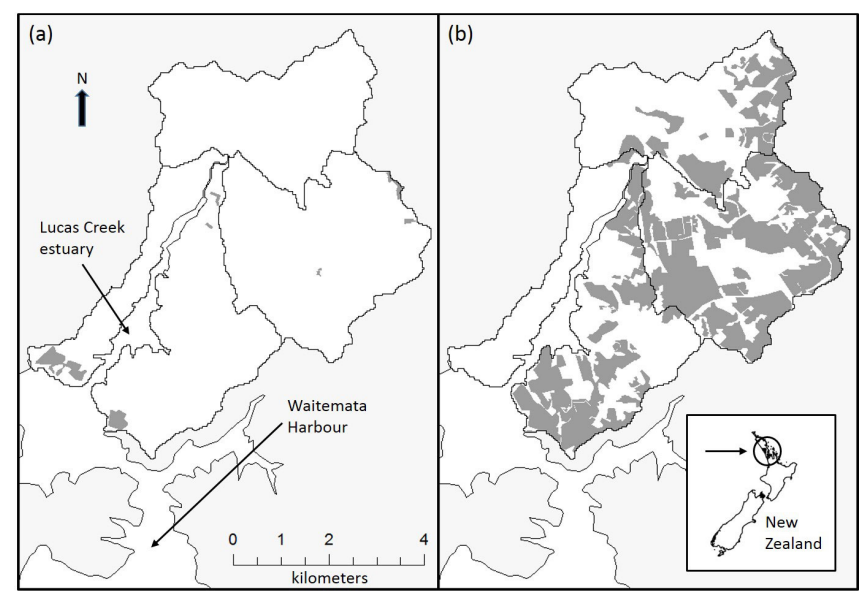

and stream management (Table 4). Scenarios 1 and 2 took as their starting point the state of the catchment in 2010 (posthistoric urban development), with baseline biophysical conditions in the Lucas Creek tidal inlet consistent with observations from the early 2000s. Scenario 1 is the conventional development scenario, characterized by low-density greenfield residential development, the use of stormwater and construction earthworks controls consistent with historic guidelines and without restoration of stream riparian margins. In contrast, Scenario 2 accommodated the increase in dwellings through residential infill and highdensity development according to WSUD principles, applied best practice stormwater management (including retrospectively to areas of historic development) and construction earthworks controls, and had substantial restoration of stream riparian margins (20 m width along both sides of $90 \%$ of the total stream length).

Scenarios 3 to 6 assumed the hypothetical situation of there having been no urban development in the catchment over the 1960-2010 period. In these scenarios, the predominantly rural land use that existed in 1960 (prehistoric urban development; Fig. 5a) was adopted as the baseline land use in 2010. Scenarios 3 and 4 assumed baseline biophysical conditions in Lucas Creek tidal inlet consistent with this rural land use while scenarios 5 and 6 adopted modified baseline biophysical conditions deliberately designed to generate a high predevelopment score for environmental well-being. The adoption of these various starting points aimed to allow comparison of resilience indicator scores calculated for situations in which there may be prior urban or rural land use legacy effects with those in which there are no legacy effects. Although all four scenarios contemplated high-density forms of residential development, Scenarios 3 and 5 adopted conventional approaches to catchment management (consistent with Scenario 1) while Scenarios 4 and 6 were consistent with WSUD principles (consistent with Scenario 2).

Scenarios 1 to 6 all involved development over the first 25 years of the study time frame of 2010-2060, with development assumed to be complete by 2035 . This is broadly consistent with Auckland Council growth projections, which forecast only limited growth after this date. In contrast, Scenario 7 involved development over the second half of the study time frame, in order to investigate the influence of development phasing on resilience indicator scores. In all other respects, Scenario 7 was identical to Scenario 5 , representing greenfield development with conventional catchment management in the absence of prior development legacy effects. 


\section{RESULTS}

\section{Combinations of STC and NC scores}

Figure 6 presents the combination of STC and NC scores assessed for the Lucas Creek study area following the urban development modeled in each of Scenarios 1 to 7. The combination of STC and $\mathrm{NC}$ scores associated with the historic urban land use $(\mathrm{H})$ at the baseline year of 2010 is also presented for comparison with the results of Scenarios 1 and 2. No such equivalent baseline combination of STC and NC scores is shown for Scenarios 3 to 7 , reflecting the fact that STC scores are not calculated unless urban land uses are present. Instead, horizontal lines showing the baseline NC scores alone associated with Scenarios 3 and 4 and Scenarios 5 to 7 , respectively, provide points of reference for interpreting the results of these scenarios.

Fig. 6. Resilience indicator scores following historic development $(\mathrm{H})$ and future urban development Scenarios 1 to 7, Lucas Creek catchment.

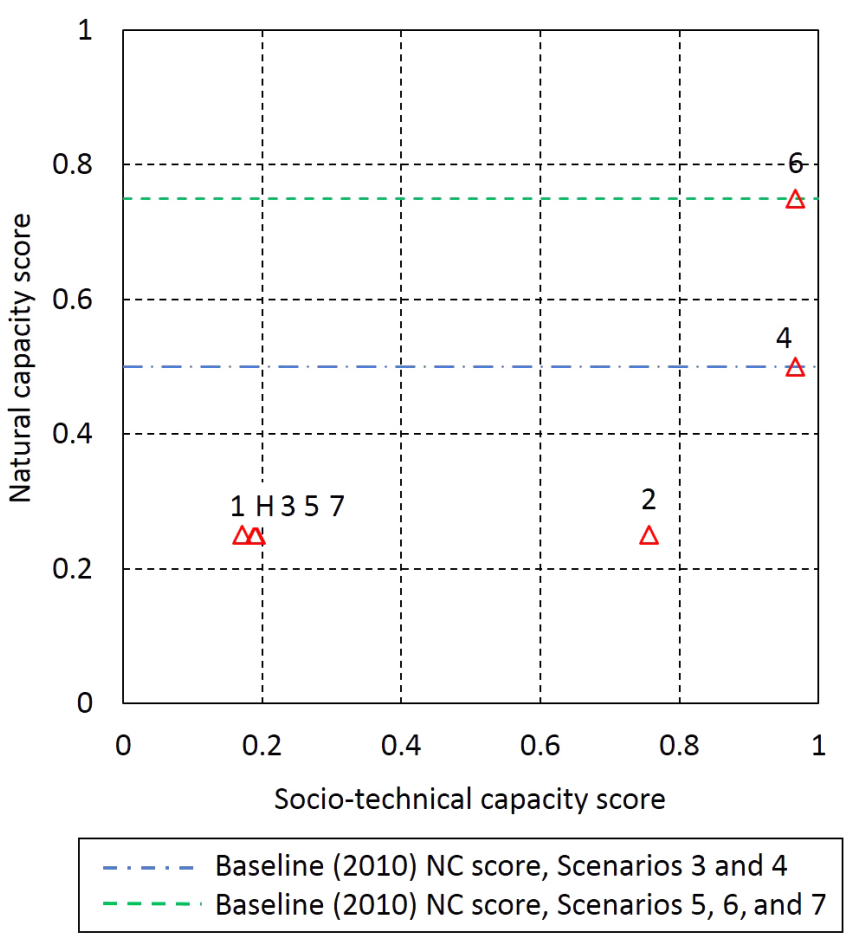

Relatively low STC and NC scores of 0.2 and 0.25 , respectively, were assessed as representing the study area as it was following historic development of the catchment to 2010 (H). With further conventional development, as contemplated in Scenario 1, the STC score dropped slightly while the NC score remained at 0.25 . Starting from the same baseline conditions, but with new development consistent with WSUD principles (Scenario 2), the STC score increased markedly to nearly 0.8 while the NC score remained at 0.25 .

A higher NC score of 0.5 was associated with the predominantly rural baseline land use preceding the urban development contemplated in Scenarios 3 and 4. Following development with conventional approaches to catchment management (Scenario 3),
STC and NC scores were assessed as being 0.2 and 0.25 , respectively. This combination of scores is identical to that assessed following the historic development of the catchment $(\mathrm{H})$ and virtually the same as that assessed for Scenario 1. In contrast, WSUD development from the rural land use baseline (Scenario 4) was assessed as having an STC score approaching the maximum value (1.0) while maintaining an $\mathrm{NC}$ score consistent with the predevelopment score (0.5). A similar but even more extreme contrast is evident in the results for Scenarios 5 and 6. In these scenarios, a relatively high baseline $\mathrm{NC}$ score of 0.75 was maintained by adopting high STC-scoring WSUD principles (Scenario 6), while the combination of markedly lower STC and $\mathrm{NC}$ scores assessed for conventional development (Scenario 5) was again identical to the combination following historic development $(\mathrm{H})$. These same STC and NC scores were also assessed for Scenario 7, in which development was identical to that in Scenario 5 other than being delayed to the second half of the study time frame.

\section{Socio-technical capacity criteria}

Table 5 presents the scores for the five criteria that constitute the STC indicator. The scores for Scenarios 1, 3, 5, and 7 were similar to those following historic development: modularity and redundancy scores were zero, while multifunctionality, diversity, and connectivity scores were all relatively low, lying in the range 0.2 to 0.43 . Although Scenario 1, 3, and 5 scores for multifunctionality and diversity were slightly higher than those following the historic development, the reverse was true for the connectivity score.

Table 5. Socio-technical capacity criteria scores following historic development $(\mathrm{H})$ and future urban development Scenarios 1 to 7, Lucas Creek catchment.

\begin{tabular}{lcccccccc}
\hline \hline & \multicolumn{8}{c}{ Scenario } \\
\cline { 2 - 9 } Criterion & $\mathrm{H}$ & 1 & 2 & 3 & 4 & 5 & 6 & 7 \\
\hline Multifunctionality & 0.33 & 0.34 & 0.75 & 0.37 & 1.00 & 0.37 & 1.00 & 0.37 \\
Modularity & 0.00 & 0.00 & 0.75 & 0.00 & 1.00 & 0.00 & 1.00 & 0.00 \\
Redundancy & 0.00 & 0.00 & 0.81 & 0.00 & 1.00 & 0.00 & 1.00 & 0.00 \\
Diversity & 0.20 & 0.21 & 0.75 & 0.25 & 1.00 & 0.25 & 1.00 & 0.25 \\
Connectivity & 0.43 & 0.31 & 0.72 & 0.33 & 0.84 & 0.33 & 0.84 & 0.33
\end{tabular}

Scores for all five criteria were markedly higher in Scenarios 2, 4, and 6. In Scenario 2 scores for the five criteria varied between 0.72 and 0.81 while in Scenarios 4 and 6 only the connectivity criterion (0.84) failed to score the maximum of 1.0.

\section{Natural capacity components}

The EW indicator at 2060 was modeled as falling in the lowmedium category under all Scenarios, other than Scenarios 4 and 7 (medium) and Scenario 6 (medium-high). These differences reflected differences in the modeled levels of the environmental well-being subindicators benthic health and muddiness (Table 6). Although both subindicators were generally modeled as falling in the low category, in Scenario 4 benthic health was modeled as medium, in Scenario 6 both subindicators were modeled as medium, and in Scenario 7 benthic health was modeled as lowmedium and muddiness as medium. The third subindicator of 
Table 6. Natural capacity components following historic development $(\mathrm{H})$ and future urban development Scenarios 1 to 7 , Lucas Creek catchment. Environmental well-being (EW) and subindicators (subin.) fall into one of the following categories: low (L), low-medium (L-M), medium (M), or medium-high (M-H). The rate of change in EW is either no change (NC) or slow decline (SD).

\begin{tabular}{|c|c|c|c|c|c|c|c|c|c|}
\hline \multirow[b]{2}{*}{ Component } & & \multicolumn{8}{|c|}{ Scenario } \\
\hline & & $\mathrm{H}$ & 1 & 2 & 3 & 4 & 5 & 6 & 7 \\
\hline EW & & L-M & $\mathrm{L}-\mathrm{M}$ & L-M & L-M & M & $\mathrm{L}-\mathrm{M}$ & M-H & $\mathrm{M}$ \\
\hline \multirow[t]{3}{*}{ EW subin. } & Benthic health & L-M & $\mathrm{L}$ & $\mathrm{L}$ & $\mathrm{L}$ & M & $\mathrm{L}$ & M & L-M \\
\hline & Sediment Accm. Rate & $\mathrm{M}-\mathrm{H}$ & M-H & M-H & M-H & $\mathrm{M}-\mathrm{H}$ & M-H & M-H & M-H \\
\hline & Muddiness $^{\dagger}$ & $\mathrm{L}$ & $\mathrm{L}$ & $\mathrm{L}$ & $\mathrm{L}$ & $\mathrm{L}$ & M & M & M \\
\hline \multicolumn{2}{|c|}{ Rate of change in EW } & $\mathrm{NC}$ & $\mathrm{NC}$ & $\mathrm{NC}$ & $\mathrm{NC}$ & $\mathrm{NC}$ & $\mathrm{NC}$ & $\mathrm{NC}$ & SD \\
\hline
\end{tabular}

environmental well-being, sediment accumulation rate, was consistently modeled as medium-high across all scenarios. With the exception of Scenario 7 , the rate of change in environment well-being at 2060 fell into the "no change" category. In Scenario 7 , the rate of change fell in the "slow decline" category.

\section{DISCUSSION}

\section{Interpretation of results}

The combination of the STC and NC scores following historic development of the catchment to 2010 (Fig. 6) indicates that the management of stormwater contaminants has been of limited effectiveness. Sediments and metals have accumulated in the estuary and, consequently, the urban aquatic SES has a relatively low level of resilience in its capacity to support the provision of ecosystem services. Further development of the catchment along conventional lines (Scenario 1) results in virtually no change to this situation. In contrast, the adoption of WSUD development approaches (Scenario 2) results in a marked improvement in the STC score, reflecting the transformation to a form of stormwater management characterized by multifunctionality, redundancy, modularity, and diversity and the restoration of stream network connectivity. Despite this approach building socio-technical capacity, the NC score remains unchanged from the level assessed following historic development $(\mathrm{H})$. This indicates that the new way of managing development is unable to reverse the previous deterioration in the condition of the receiving environment and consequently, ecosystem service provision remains highly vulnerable.

In the remaining scenarios, predevelopment natural capacity is at moderate (Scenarios 3 and 4) or relatively high (Scenarios 5, 6, and 7) levels, indicating lower levels of sediment and metal accumulation. Development of the catchment according to conventional approaches under Scenarios 3 and 5 results in the NC score falling to the same level as assessed for the historic development situation $(\mathrm{H})$, irrespective of predevelopment conditions. This indicates situations in which a failure to build socio-technical capacity into stormwater management results in a marked reduction in the resilience of the receiving environment to provide ecosystem services as sediment and metals accumulate. These scenarios simply replicate the system trajectory followed as a result of the historic development of the catchment, although the extent of the loss of natural capacity varies as a function of predevelopment conditions. Under Scenario 7, the condition of the receiving environment undergoes a less marked decline than under Scenarios 3 and 5 but, reflecting the increasing vulnerability associated with its continuing downward trajectory, the NC score is assigned the same value (0.25) as Scenarios 3 and 5 .

In contrast to these Scenarios, the adoption of WSUD approaches to development (Scenarios 4 and 6) foster high levels of socio-technical capacity that enable much more effective management of stormwater contaminants. Consequently, there is less marked deterioration in receiving environment conditions under these scenarios, to the extent that, despite development, natural capacity and consequently, system resilience are maintained at the predevelopment level.

\section{Evaluation of the method}

We evaluated the performance of the method by considering three criteria: (1) its ability to discriminate between scenarios; (2) the extent to which results reflect resilience concepts; and (3) the extent to which the method enhances the utility of the DSS by providing additional information to complement that provided by other indicators. We then considered limitations and directions for further research.

\section{Ability to discriminate}

In the seven scenarios that we modeled, the STC score provided clear discrimination between alternative development approaches, varying between approximately 0.2 and 1.0. All scenarios had at least some level of stormwater treatment and riparian vegetation, avoiding STC scores in the range zero to 0.2. Despite this constraint on the lower limit, the range of scores (approximately 0.8 ) provides an indication that the STC score is sufficiently sensitive to discriminate between other development scenarios not considered here. Scenarios comprising hybrid conventional and WSUD developments, for instance, can be expected to have intermediate STC scores that provide a clear distinction from "pure" WSUD scenarios at one end of the spectrum and "pure" conventional scenarios at the other.

There was less marked variation in NC scores, ranging from 0.25 in all conventional development scenarios to 0.75 in Scenario 6. Although the results successfully discriminated between WSUD and conventional scenarios, the characteristics of the receiving environment constrained the range over which scores could vary. At the lower end, the minimum $\mathrm{NC}$ score of 0.25 reflected the 
low-medium level of environmental well-being modeled from the levels of the three contributing components: the benthic health, muddiness, and sediment accumulation rate indicators. Despite the benthic health and muddiness indicators being at their lowest level in conventional development scenarios, the relatively high score for the sediment accumulation rate indicator prevented environmental well-being, and consequently the $\mathrm{NC}$ score, from falling to its lowest level. The maximum NC score of 0.75 reflected the fact that, even with the adoption of WSUD development approaches, the DSS predicted a decline in the benthic health and muddiness indicators, and consequently in environmental wellbeing, as a result of relatively low levels of sediment and metal accumulation in the receiving environment. The method is only likely to deliver an NC score in excess of 0.75 where relatively pristine predevelopment conditions exist, urban development is relatively limited in its extent, and a high level of socio-technical capacity fosters highly effective management of stormwater contaminants.

\section{Reflection of resilience concepts}

According to resilience theory, SESs are characterized as existing in multiple, distinct regimes or states (Walker et al. 2004, Folke et al. 2010). An SES can move from one regime to another in response to a steady change in a forcing variable that causes the system to cross a threshold (Walker et al. 2012). A key aspect of this characterization of SESs is that once a threshold has been crossed, the system exhibits hysteresis, such that a reversal in the forcing variable does not result in the system returning across the threshold to its original regime (Scheffer et al. 2001, Kinzig et al. 2006).

This characterization of the response of SESs is mimicked in the way in which the STC and NC scores interact in the Lucas Creek catchment study. In Scenarios 4 and 6, a high level of sociotechnical capacity limits the discharge of stormwater contaminants to the receiving environment, maintaining a relatively high level of natural capacity in the system. This combination of relatively high STC and NC scores can be thought of as Regime A. In Scenarios 3 and 5 and under the historic development of the catchment, low STC-scoring conventional development approaches fail to prevent the accumulation of contaminants in the receiving environment, resulting in a marked loss in the natural capacity of the system. The resultant combination of relatively low STC and NC scores can be thought of as Regime B, acting as a basin of attraction (Walker et al. 2004) at which the SES will arrive unless highly effective stormwater management is employed, irrespective of starting conditions. Movement away from Regime B appears to be constrained, consistent with the presence of hysteresis in the system response. In Scenario 2, WSUD development builds socio-technical capacity and this improves on the management of stormwater contaminants that occurred under the previous historic development phase. However, despite a marked improvement in the STC score, there is no corresponding improvement in the natural capacity of the system. This reflects the characteristics of the Lucas Creek estuary, which acts as a sink for stormwater contaminants. Better catchment management has no impact on the legacy effects of the historic development phases. Instead of a return to Regime A, the system enters a new regime, Regime $C$, characterized by high socio-technical capacity but low natural capacity. Notably, this ability of the method to mimic key resilience concepts is an emergent property, rather than one that was explicitly designed.

\section{Enhancement of DSS utility}

The assessment and reporting of resilience indicators provides the DSS with a way to portray, in a snap-shot, the interaction of catchment management effort and outcomes. Previously, users of the DSS were only able to compare the outcomes of different development scenarios by reflecting on the response of a range of environmental, economic, social, and cultural indicators to variations in a range of catchment management characteristics. The STC and NC scores provide integrating metrics of the form of development and system response, respectively. As we found in the Lucas Creek demonstration study, the combination of scores reveals much about the behavior of the system: for instance, its responsiveness to better management practices and the constraining influence of historical legacy effects.

Furthermore, the components upon which the scoring of the STC and $\mathrm{NC}$ indicators is based provide information that is not readily apparent from the original suite of four well-being indicators. The four well-being indicators are constrained to providing an assessment at a given point in time rather than expressing the potential for the system state to be maintained or improved in the future, a limitation that has been recognized in the use of sustainability indicators elsewhere (Milman and Short 2008). Although the NC score also reflects the system state at this same point in time, it also takes account of the trajectory of the system. Although under most of the poorly scoring scenarios a low $\mathrm{NC}$ score reflected a low environmental well-being score, under Scenario 7, a low NC score also indicated the increasing vulnerability of a currently less-compromised system. Information reported by the DSS allows users to investigate the extent to which the trajectory of the system influences the NC score. Similarly, the reporting of the scores for the individual criteria underlying the STC score allows users of the DSS to evaluate the strengths and weaknesses of a specified scenario. Although the calculation of scores for certain of the criteria take into account common inputs, notably the extent of WSUD, there is sufficient independence between the criteria for them each to add meaning to the evaluation of a given catchment management approach. The multifunctionality and diversity scores convey information on the contribution of stormwater management devices to system resilience; the modularity and redundancy scores reflect the differing influence of green- and brownfield development on opportunities to build technical resilience into stormwater systems; and the connectivity score provides information on the contribution that stream management makes toward system resilience.

\section{Limitations and further development}

The STC and NC indicators have been explicitly developed to provide for a relative assessment of resilience that uses information readily available from inputs to, and outputs from, the DSS. However, these indicators do not attempt to provide an absolute assessment of system resilience relative to established biophysical thresholds, nor do they comprehensively capture the range of socio-technical characteristics that influence the capacity to plan for, or manage and respond to, increasing vulnerability. Furthermore, the assessment methods involve adopting deliberately simple assumptions and calculation methods, for 
instance, projecting future indicator scores from an assumed linear system response and giving subindicators equal weighting in the calculation of indicators. Accordingly, although the results described here demonstrate the potential of the methods, they require significant further development and evaluation before application in a decision-making context.

This will involve, first, investigating alternative approaches for the calculation of the NC score, for instance, using biophysical metrics such as sediment metal concentrations, which are routinely measured as part of environmental monitoring programs and for which thresholds can be derived from ecotoxicological guideline values (for example, MacDonald et al. 1996). Further development of the methods for assessing the NC score should also investigate alternative calculation methods that account for nonlinearity in the response of systems (Scheffer et al. 2001). Second, methods are required to allow assessment of the social components of socio-technical capacity in addition to the physically based technical criteria adopted here. Institutional characteristics, social capital, community engagement, and adaptive capacity have been found to be of key significance for the resilience of SESs and transformations in urban water management (Walker and Salt 2006, Brown 2008, Shandas and Messer 2008, Collier et al. 2013, Rijke et al. 2013). Because these characteristics are not readily assessed from outputs of the DSS, further development of the methods for assessing the STC indicator should investigate their deployment in settings other than the application of the DSS. Finally, alternative methods for combining subindicator scores, such as the geometric mean or minimum operator (Smith 1990), should be evaluated for their potential to better reflect the interaction between subindicators when calculating the NC and STC indicator scores.

\section{CONCLUSION}

Resilience concepts provide a novel basis for discriminating between outcomes associated with WSUD and alternative forms of urban development. We developed and evaluated a method for assessing the capacity of urban aquatic SESs to provide ecosystem services in the face of stormwater-related development effects. Consistent with the recommendations of other authors, the method considers socio-technical and ecological aspects of resilience, is grounded in theory, is context specific, and provides insights into system dynamics (Angeler and Allen 2016, Quinlan et al. 2016).

The method has been shown to provide discrimination between WSUD and conventional urban development scenarios, within constraints arising from the biophysical characteristics of the environment and the nature of the scenarios evaluated. In a case study evaluation of the method, WSUD scenarios were assessed as having relatively high social-technical capacity, consistent with descriptions by previous authors (Wong and Brown 2009, Woods Ballard et al. 2015). In contrast, the results of the case study indicate that adoption of a WSUD approach may not always result in a better outcome in terms of the natural capacity of an SES. Consistent with key concepts of resilience theory, outcomes were grouped in a limited number of system states or regimes, with evidence that transformations between states exhibit hysteresis. In some scenarios, the influence of the adoption of WSUD on the state of the system was constrained by the legacy degradation of the depositional estuarine environment. This is an important point: although the socio-technical superiority of WSUD gives it the potential to perform better than conventional forms of urban development in fostering resilience in the provision of ecosystem services, such an outcome is contingent on the predevelopment state of the receiving environment. Nemec et al. (2013) described a similar response in relation to a river recovery program in a dammed watershed: despite marked improvements in aspects of social resilience, ecological aspects of resilience remained little changed as a result of the continuing impact of the dam. Elsewhere, the limited success of improved management approaches to address the effects of previous environmental degradation has been found to be a recurring characteristic of attempts to restore coastal ecosystems (Duarte et al. 2015).

Although the resilience indicators described here have been shown to provide a source of additional, valuable information complementary to that provided by a range of other well-beingbased indicators incorporated in the DSS, they are limited to providing a relative assessment of system resilience based on simplistic approaches to characterizing system response and aggregating subindicators. Further development of the method should aim to extend the assessment of resilience by considering other fundamental biophysical and social properties of urban aquatic SESs.

Responses to this article can be read online at: http://www.ecologyandsociety.org/issues/responses. $\mathrm{php} / 9727$

Acknowledgments:

This research was conducted as part of the Resilient Urban Futures programme funded by the New Zealand Ministry for Business, Innovation and Employment under contract UOOX1203.

\section{LITERATURE CITED}

Ahern, J. 2011. From fail-safe to safe-to-fail: sustainability and resilience in the new urban world. Landscape and Urban Planning 100:341-343. http://dx.doi.org/10.1016/j.landurbplan.2011.02.021

Albers, M., and S. Deppisch. 2013. Resilience in the light of climate change: useful approach or empty phrase for spatial planning? European Planning Studies 21(10):1598-1610. http://dx. doi.org/10.1080/09654313.2012.722961

Alfsen, C., A. Duval, and T. Elmqvist. 2011. The urban landscape as a social-ecological system for governance of ecosystem services. Pages 213-218 in J. Niemelä, J. H. Breuste, T. Elmqvist, G. Guntenspergen, P. James, and N. E. McIntyre, editors. Urban ecology: patterns, processes, and applications. Oxford University Press, Oxford, UK. http://dx.doi.org/10.1093/acprof: oso/9780199563562.003.0026

Allan, P., and M. Bryant. 2011. Resilience as a framework for urbanism and recovery. Journal of Landscape Architecture 6 (2):34-45. http://dx.doi.org/10.1080/18626033.2011.9723453

Allen, C. R., L. Gunderson, and A. R. Johnson. 2005. The use of discontinuities and functional groups to assess relative resilience 
in complex systems. Ecosystems 8:958-966. http://dx.doi. org/10.1007/s10021-005-0147-X

Angeler, D. G., and C. R. Allen. 2016. Quantifying resilience. Journal of Applied Ecology 53:617-624. http://dx.doi. org/10.1111/1365-2664.12649

Birkmann, J., D. Seng, T. Abeling, N. Huq, J. Wolfertz, N. Karanci, G. İkizer, C. Kuhlicke, M. Pelling, J. Forrester, M. Fordham, H. Deeming, S. Kruse, and S. Jülich. 2012. Systematization of different concepts, quality criteria, and indicators. Work package 1, deliverable 1.2. emBRACE project, Seventh Framework Programme, EU, Brussels, Belgium [online] URL: https://drive.google.com/file/d/0B9RBeBGSyVgFckpCcORjeXhqZFk/edit

Bollund, P., and S. Hunhammar. 1999. Ecosystem services in urban areas. Ecological Economics 29:293-301. http://dx.doi. org/10.1016/S0921-8009(99)00013-0

Brown, R. R. 2008. Local institutional development and organizational change for advancing sustainable urban water futures. Environmental Management 41:221-233. http://dx.doi. org/10.1007/s00267-007-9046-6

Burthe, S. J., P. A. Henrys, E. B. Mackay, B. M. Spears, R. Campbell, L. Carvalho, B. Dudley, I. D. M. Gunn, D. G. Johns, S. C. Maberly, L. May, M. A. Newell, S. Wanless, I. J. Winfield, S. J. Thackeray, and F. Daunt. 2016. Do early warning indicators consistently predict non-linear change in long-term ecological data? Journal of Applied Ecology 53:666-676. http://dx.doi. org/10.1111/1365-2664.12519

Butler, D., and J. Davies. 2009. Urban drainage. Third edition. Spon, Abingdon, UK.

Carpenter, S., B. Walker, J. M. Anderies, and N. Abel. 2001. From metaphor to measurement: resilience of what to what? Ecosystems 4:765-781. http://dx.doi.org/10.1007/s10021-001-0045-9

Carpenter, S. R., F. Westley, and M. G. Turner. 2005. Surrogates for resilience of social-ecological systems. Ecosystems 8:941-944. http://dx.doi.org/10.1007/s10021-005-0170-y

Collier, M. J., Z. Nedović-Budić, J. Aerts, S. Connop, D. Foley, K. Foley, D. Newport, S. McQuaid, A. Slaev, and P. Verberg. 2013. Transitioning to resilience and sustainability in urban communities. Cities 32:S21-S28. http://dx.doi.org/10.1016/j. cities.2013.03.010

Duarte, C. M., A. Borja, J. Carstensen, M. Elliott, D. KrauseJensen, and N. Marbà. 2015. Paradigms in the recovery of estuarine and coastal ecosystems. Estuaries and Coasts 38 (4):1202-1212. http://dx.doi.org/10.1007/s12237-013-9750-9

Fletcher, T. D., W. Shuster, W. F. Hunt, R. Ashley, D. Butler, S. Arthur, S. Trowsdale, S. Barraud, A. Semadeni-Davies, J.-L. Bertrand-Krajewski, P. S. Mikkelsen, G. Rivard, M. Uhl, D. Dagenais, and V. Viklander. 2014. SUDS, LID, BMPs, WSUD and more - the evolution and application of terminology surrounding urban drainage. Urban Water Journal 12(7):525-542. http://dx.doi.org/10.1080/1573062X.2014.916314

Folke, C., S. R. Carpenter, B. Walker, M. Scheffer, T. Chapin, and J. Rockström. 2010. Resilience thinking: integrating resilience, adaptability and transformability. Ecology and Society 15(4):20. http://dx.doi.org/10.5751/ES-03610-150420
Göbel, P., C. Dierkes, and W. Coldewey. 2007. Storm water runoff concentration matrix for urban areas. Journal of Contaminant Hydrology 91:26-42. http://dx.doi.org/10.1016/j.jconhyd.2006.08.008

Gómez-Baggethun, E., and D. N. Barton. 2013. Classifying and valuing ecosystem services for urban planning. Ecological Economics 86:235-245. http://dx.doi.org/10.1016/j.ecolecon.2012.08.019

Hoyer, J., W. Dickhaut, L. Kronawitter, and B. Weber. 2011 Water sensitive urban design: principles and inspiration for sustainable stormwater management in the city of the future. Jovis, Berlin, Germany.

Kinzig, A. P., P. Ryan, M. Etienne, H. Allison, T. Elmqvist, and B. H. Walker. 2006. Resilience and regime shifts: assessing cascading effects. Ecology and Society 11(1):20. http://dx.doi. org/10.5751/ES-01678-110120

Lewis, M., J. James, E. Shaver, S. Blackbourn, A. Leahy, R. Seyb, R. Simcock, P. Wihongi, E. Sides, and C. Coste. 2015. Water sensitive design for stormwater, Auckland Council guideline document GD2015/004. Auckland Council, Auckland, New Zealand.

Lundy, L., and R. Wade. 2011. Integrating sciences to sustain urban ecosystem services. Progress in Physical Geography 35 (5):653-669. http://dx.doi.org/10.1177/0309133311422464

MacDonald, D. D., R. S. Carr, F. D. Calder, E. R. Long, and C. G. Ingersoll. 1996. Development and evaluation of sediment quality guidelines for Florida coastal waters. Ecotoxicology 5:253-278. http://dx.doi.org/10.1007/BF00118995

McDonald, R., and P. Marcotullio. 2011. Global effects of urbanization on ecosystem services. Pages 193-205 in J. Niemelä, J. H. Breuste, T. Elmqvist, G. Guntenspergen, P. James, and N. E. McIntyre, editors. Urban ecology: patterns, processes, and applications. Oxford University Press, Oxford, UK. http://dx.doi. org/10.1093/acprof:oso/9780199563562.003.0024

Milman, A., and A. Short. 2008. Incorporating resilience into sustainability indicators: an example for the urban water sector. Global Environmental Change 18:758-767. http://dx.doi. org/10.1016/j.gloenvcha.2008.08.002

Moores, J., C. Batstone, J. Gadd, M. Green, S. Harper, A. Semadeni-Davies, and R. Storey. 2014. Evaluating the sustainability of urban development in New Zealand in relation to effects on water bodies. International Journal of Environmental Sustainability 9(4):31-47. http://dx.doi.org/10.18848/2325-1077/ CGP/v09i04/55108

Moores, J., and A. Semadeni-Davies. 2015. Assessing resilience in stormwater management. In 2015 Asia Pacific Stormwater Conference. Auckland, New Zealand. [online] URL: http:// sustainablecities.org.nz/wp-content/uploads/Moores_Semadeni-Davies. pdf

Mouritz, M., M. Evangelisti, and T. McAlister. 2006. Water sensitive urban design. Pages 5-1-5-22 in T. Wong, editor. Australian runoff quality. Engineers Australia, Sydney, Australia.

Nash, K. L., N. A. J. Graham, S. Jennings, S. K. Wilson, and D. R. Bellwood. 2016. Herbivore cross-scale redundancy supports response diversity and promotes coral reef resilience. Journal of Applied Ecology 53:646-655. http://dx.doi.org/10.1111/1365-2664.12430 
Nemec, K. T., J. Chan, C. Hoffman, T. L. Spanbauer, J. A. Hamm, C. R. Allen, T. Hefley, D. Pan, and P. Shrestha. 2013. Assessing resilience in stressed watersheds. Ecology and Society 19(1):34. http://dx.doi.org/10.5751/ES-06156-190134

Quinlan, A. E., M. Bérbes-Blázquez, L. J. Haider, and G. D. Peterson. 2016. Measuring and assessing resilience in practice: broadening understanding through multiple disciplinary perspectives. Journal of Applied Ecology 53:677-687. http://dx. doi.org/10.1111/1365-2664.12550

Radford, K. G., and P. James. 2013. Changes in the value of ecosystem services along a rural-urban gradient: a case study of Greater Manchester, UK. Landscape and Urban Planning 109:117-127. http://dx.doi.org/10.1016/j.landurbplan.2012.10.007

Resilience Alliance. 2010. Assessing resilience in social-ecological systems: workbook for scientists. Version 2.0. [online] URL: http:// www.resalliance.org/files/ResilienceAssessmentV2 2.pdf

Rijke, J., M. Farrelly, R. Brown, and C. Zevenbergen. 2013. Configuring transformative governance to enhance resilient urban water systems. Environmental Science \& Policy 25:62-72. http://dx.doi.org/10.1016/j.envsci.2012.09.012

Riley, A. 1998. Restoring streams in cities: a guide for planners, policy makers and citizens. Island, Washington, D.C., USA.

Roy, A. H, S. J. Wenger, T. D. Fletcher, C. J. Walsh, A. R. Ladson, W. D. Shuster, H. W. Thurston, and R. R. Brown. 2008. Impediments and solutions to sustainable, watershed-scale urban stormwater management: lessons from Australia and the United States. Environmental Management 42:344-359. http://dx.doi. org/10.1007/s00267-008-9119-1

Sabbion, P., and K. Perini. 2017. Urban sustainability and river restoration: green and blue infrastructure. John Wiley \& Sons, Chichester, UK.

Scheffer, M., J. Bascompte, W. A. Brock, V. Brovkin, S. R. Carpenter, V. Dakos, H. Held, E. H. van Nes, M. Rietkerk, and G. Sugihara. 2009. Early-warning signals for critical transitions. Nature 461:53-59. http://dx.doi.org/10.1038/nature08227

Scheffer, M., S. Carpenter, J. A. Foley, C. Folke, and B. Walker. 2001. Catastrophic regime shifts in ecosystems. Nature 413:591-596. http://dx.doi.org/10.1038/35098000

Semadeni-Davies, A. 2012 Implications of climate and urban development on the design of sustainable urban drainage systems (SUDS). Journal of Water and Climate Change 3(4):239-256. http://dx.doi.org/10.2166/wcc.2012.043

Shandas, V., and W. B. Messer. 2008. Fostering green communities through civic engagement: community-based environmental stewardship in the Portland area. Journal of the American Planning Association 74(4):408-418. http://dx.doi. org/10.1080/01944360802291265

Smith, D. G. 1990. A better water quality indexing systems for rivers and streams. Water Resources 24(10):1237-1244. http://dx. doi.org/10.1016/0043-1354(90)90047-A

The Economics of Ecosystems and Biodiversity (TEEB). 2011. TEEB manual for cities: ecosystem services in urban management. TEEB, Geneva, Switzerland. [online] URL: http://www.teebweb.
org/wp-content/uploads/Study $\% 20$ and $\% 20$ Reports/Additional $\%$ 20Reports/Manual $\% 20$ for $\% 20$ Cities/TEEB $\% 20$ Manual $\% 20$ for $\%$ 20Cities English.pdf

Thrush, S., M. Townsend, J. Hewitt, K. Davies, A. Lohrer, C. Lundquist, and K. Cartner. 2013. The many uses and values of estuarine ecosystems. Pages 226-237 in J. R. Dymond, editor. Ecosystem services in New Zealand: conditions and trends. Manaaki Whenua, Lincoln, New Zealand.

Tratalos, J., R. A. Fuller, P. H. Warren, R. G. Davies, and K. J. Gaston. 2007. Urban form, biodiversity potential and ecosystem services. Landscape and Urban Planning 83:308-317. http://dx.doi. org/10.1016/j.landurbplan.2007.05.003

Walker, B. H., S. R. Carpenter, J. Rockstrom, A.-S. Crépin, and G. D. Peterson. 2012. Drivers, "slow" variables, "fast" variables, shocks, and resilience. Ecology and Society 17(3):30. http://dx.doi. org/10.5751/ES-05063-170330

Walker, B., C. S. Holling, S. R. Carpenter, and A. Kinzig. 2004. Resilience, adaptability and transformability in social-ecological systems. Ecology and Society 9(2):5. http://dx.doi.org/10.5751/ ES-00650-090205

Walker, B., and D. Salt. 2006. Resilience thinking: sustaining ecosystems and people in a changing world. Island, Washington, D.C., USA.

Wong, T. H. F., and R. R. Brown. 2009. The water sensitive city: principles for practice. Water, Science and Technology 60 (3):673-682. http://dx.doi.org/10.2166/wst.2009.436

Woods Ballard, B., H. Udale-Clarke, S. Illman, T. Scott, R. Ashley, and R. Kellagher. 2015. The SuDS manual. CIRIA, London, UK. 